\title{
Multiobjective Optimization Model for Profile Design of Hump Distributing Zone
}

\author{
Hongliang Zhang, ${ }^{1}$ Jing Yang, ${ }^{2}$ and Taoyuan Yang ${ }^{1}$ \\ ${ }^{1}$ School of Traffic and Transportation, Beijing Jiaotong University, Beijing 100044, China \\ ${ }^{2}$ School of Civil Engineering and Transportation, Beijing University of Civil Engineering and Architecture, Beijing 100044, China \\ Correspondence should be addressed to Hongliang Zhang; hlzhang@bjtu.edu.cn
}

Received 7 July 2017; Revised 7 November 2017; Accepted 11 December 2017; Published 31 December 2017

Academic Editor: Francisco Chicano

Copyright (c) 2017 Hongliang Zhang et al. This is an open access article distributed under the Creative Commons Attribution License, which permits unrestricted use, distribution, and reproduction in any medium, provided the original work is properly cited.

Railway freight trains consist of many cars heading to different destinations. Hump is the special equipment that distributes cars with different destinations to different tracks in a marshalling station. In recent years, with the development of Chinese freight car technology, the axle load has risen from 21 ton to 23 ton and will rise to 27 ton in the future. Many rolling problems appear in the hump distributing zone with the application of 23-ton axle load cars, which will be exacerbated by 27 -ton axle load cars. This paper proposes a multiobjective optimization model based on the angle of the hump profile design with minimizing weighted accumulating rolling time (WART) and hump height as optimization goals and uses the improved genetic algorithm NSGA-II to determine a solution. In case study, Pareto solution set is obtained, and the contrast analysis with traditional method is made.

\section{Introduction}

Marshalling station is the station that disassembles, sorts, and reassembles freight trains to different destinations and the hump is the disassembling equipment in marshalling station (shown in Figure 1). Trains are pushed gradually up a raised portion of track called the "hump." Wagons are uncoupled before arriving at the crest and then coast to the desired tracks in the classification yard under the force of gravity. The distributing zone of the hump is the bottle neck of the marshalling station and has an important influence on operational efficiency and safety.

In China, most humps were built or rebuilt in the 1980s and 1990s. The design of the cars has an $18 \mathrm{t}$ and $21 \mathrm{t}$ axle load with sliding bearings [1, 2]. With the development of railway wagon technology, the sliding bearing has been replaced by the rolling bearing, which has better rolling performance [3], and the axle load of the car has increased to $23 \mathrm{t}$. The $18 \mathrm{t}$ and $21 \mathrm{t}$ axle load cars are not the main transport cars any more. With the application of the $23 \mathrm{t}$ axle load car, problems such as over rolling speed and insufficient braking power have arisen [4-8]. Although problems can be temporarily relieved by reducing humping speed and adding more piston retarders, the humping capacity will decrease and the situation will be exacerbated with the application of $27 \mathrm{t}$ axle load cars in the future [9-11]. In essence, it is a problem that the hump distributing profile does not match wagon development trends, which is a problem better solved by design optimization.

\section{Literature Review}

In the field of hump operation, Adlbrecht et al. [12] propose a Mixed Integer Programme (MIP) under consideration of single-block (a block refers to rail cars that share the same destination) trains. Then conduct a series of numerical experiments and show that the solutions of the MIP improve by $10 \%$ on average. Shi and Zhou [13] present a time-expanded multilayer network flow model to describe the connection between different layers of yard operations and develop a mixed integer programming model to optimize the overall performance by jointly considering tightly interconnected facilities. Li et al. [14] propose sequencing and scheduling model considering multiple engines and inspection groups and got solution by existing commercial optimization solvers for one typical planning horizon. Bektaş et al. [15] propose 


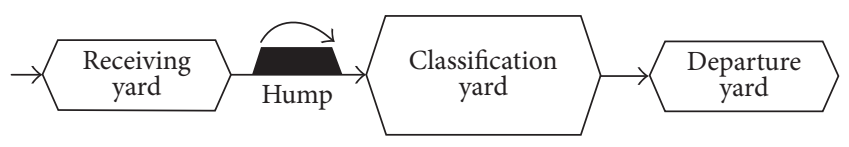

FIGURE 1: Composition of marshalling station.

methodology performs dynamic reassignments of empty cars through a fast and efficient solution procedure based on the assignment algorithm. Dick and Dirnberger [16] introduce a hump simulation system (named HYSS) as a research tool to examine how its various outputs can be used to quantify terminal performance and described the planned research program aimed at advancing the science of hump yard design and operations. Yagar et al. [17] proposed a computer model for sequencing trains into the rail yard humping process. The model establishes an efficient hump sequence by promoting compatibility between inbound trains and departing trains, as well as operator service priorities. Dynamic programming is used to minimize overall rail yard throughput costs for a given interval of operation. Marton et al. [18] combine an integer programming approach and a computer simulation tool to develop and verify an improved classification schedule for a real-world train classification instance. Lin and Cheng [19] introduce a simulation model which depicts typical operations in a railroad hump yard and present key performance measurements that are used to gauge the efficiency of yard operations and infrastructure. Boysen et al. [20] introduce and discuss the train makeup problem, analyze its complexity status, and develop suitable exact and heuristic solution procedures that are tested in a comprehensive computational study.

In hump design fields, Zhang et al. [21] propose a multiobjective optimization model for coupling area in marshalling yard with rolling distance of middle car under adverse condition and hard rolling car under favorable condition which are taken as optimization objectives. Zhang et al. [22] analyze the shortage of monthly meteorological data usage of the Code for Design on Hump and Marshalling Yard of Railway and the effect on hump design and propose the suggestion that at least daily meteorological data should be used for hump design. Huang [23] and Zhang [24] both establish multiobjective models and provide the solution algorithms. However, their optimization objectives need to be studied. In Huang's paper, the optimization objectives are hump height and humping speed. In actual situations, the humping speed is not a suitable optimization objective. Since the uncoupling work is performed manually, increasing the humping speed can make the operator fall behind, which will lead to accidents in the shunting operation. In China, the humping speeds are usually $0.83 \mathrm{~m} / \mathrm{s}, 1.39 \mathrm{~m} / \mathrm{s}$, and $2.22 \mathrm{~m} / \mathrm{s}$ for a single car, small group of cars, and large blocks of cars, respectively, and the design speed is $1.39 \mathrm{~m} / \mathrm{s}$. As a result, the optimization objective is not suitable. In Zhang's paper, the optimization objectives are interval time between rolling cars, hump height and amount of braking equipment. The interval time cannot be reduced infinitely, because the turnouts and the friction retarders need a certain time to change their working state for the continuous decoupling

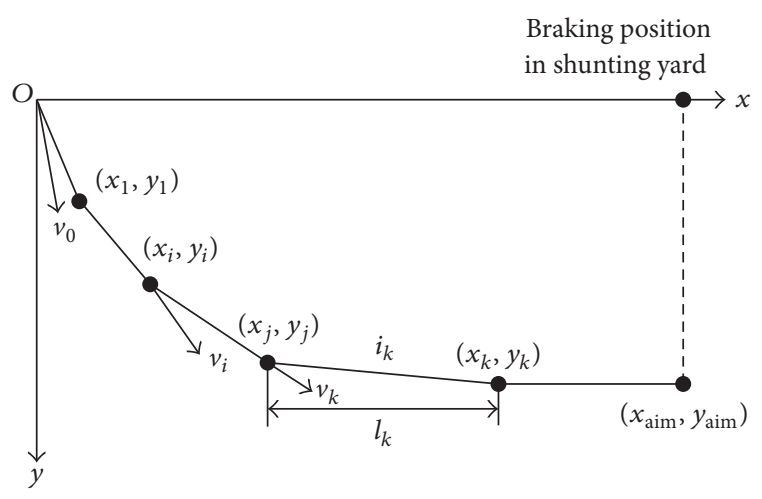

FIGURE 2: Coordinate system of hump distributing zone.

of wagons. Therefore, it is also not suitable to be used for optimization.

In the field of multiobjective optimization, Deb et al. [25] propose a nondominated sorting based multiobjective evolutionary algorithm (NSGA-II). Zhang and Ma [26] establish a multiobjective optimal model which simultaneously considers the two objectives of minimizing the production cost and minimizing the operation cost for the dry-type air-core reactor problem and then propose a memetic evolutionary algorithm which combines an elitist nondominated sorting genetic algorithm version II (NSGA-II) with a local search strategy based on the covariance matrix adaptation evolution strategy (CMA-ES). Li et al. [27] propose a multiobjective reverse logistics network optimization model that considers the objectives of the cost, the total tardiness of the cycle time, and the coverage of customer zones. The NSGA-II is employed for solving it.

Above all, the hump distributing zone design has not been solved perfectly. This paper aims to provide an optimization method for a hump distributing zone design for the upcoming $27 \mathrm{t}$ axle load car in China. The paper is organized as follows. The proposed model, solution algorithm and coefficient calibration are described in Section 3. A case study which validates the effectiveness of the proposed approach is described in Section 4. Finally, Section 5 discusses conclusions.

\section{Methodology}

The hump distributing zone is located between the hump crest and entry to the braking position in the classification yard. The profile design of the hump distributing zone is the vertical design of hard rolling track that has the maximum total resistance in all shunting tracks.

Before modeling, for calculation convenience, a coordinate system needs to be established. The gradient change point of the hump crest and acceleration gradient is set as the origin of the coordinate system, with the vertical downward direction as the $y$-axis direction and the rolling direction as the $x$-axis direction. The $x$-coordinate of a gradient change point indicates horizontal distance, and the $y$-coordinate indicates hump height. As shown in Figure 2, the black points are the gradients change points, $x_{k}$ indicates the horizontal 


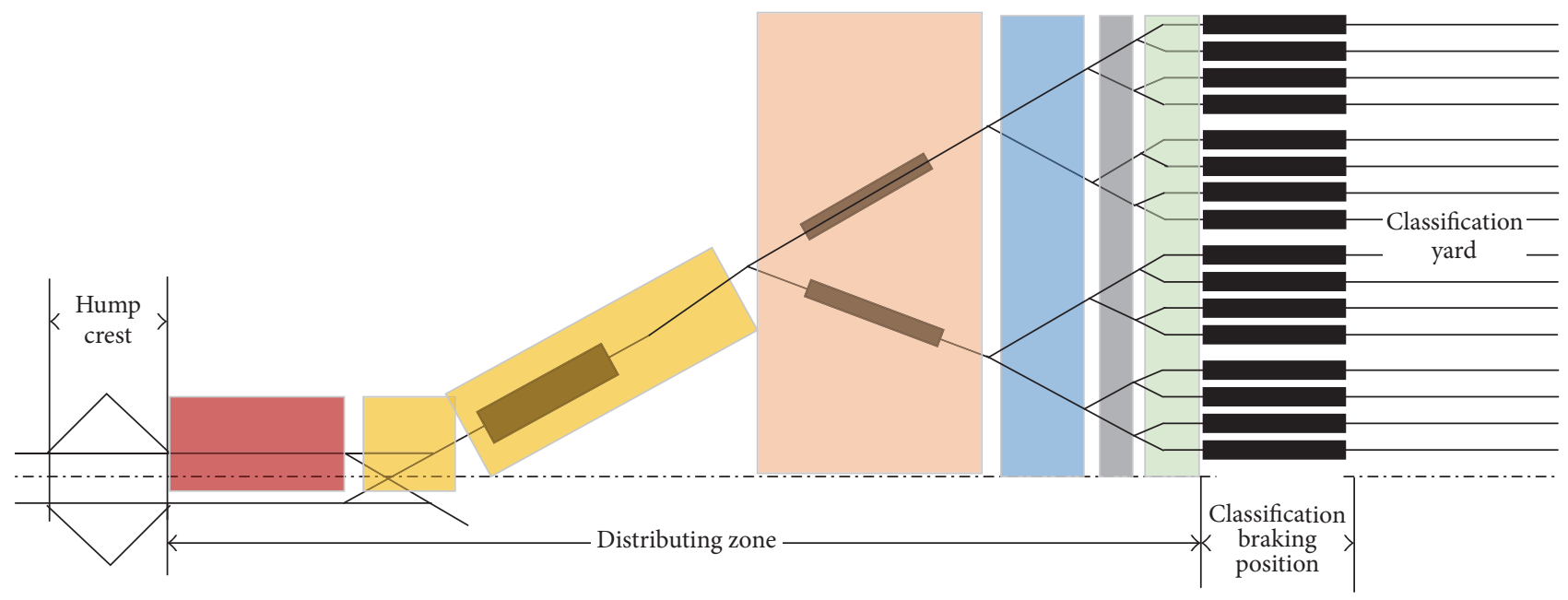

FIGURE 3: Sketch map of rolling time weight in distributing zone (half range).

distance of point $k$ from the hump crest, and $y_{k}$ indicates the vertical distance from the hump crest. $v_{k}$ indicates the speed of a coasting wagon at point $k$.

3.1. Optimization Targets. The hump is used for car classification. Making the cars pass through the distributing zone as quickly as possible and meeting the speed demands of the control system is the goal of optimization, which can be divided into two optimization targets:

\subsubsection{Weighted Accumulated Rolling Time (WART) of Profile} Design Calculating Car. Rolling time is an important index for distributing zone evaluation. With branching turnout as a dividing point, different sections connect different numbers of tracks and have different traffic volumes. Taking a 32-track classification yard, for example, half of the range is shown in Figure 3, all cars to be classified will pass through the red area, in the yellow area about $1 / 2$ of rolling cars pass through (to maximum use of the capacity of shunting yard, tracks with few traffic volumes will share with large ones nearby, so the traffic volume of each track is relatively balanced), with about $1 / 4$ for orange, about $1 / 8$ for blue, about $1 / 16$ for gray, and about $1 / 32$ for blue. Therefore, the red area is the busiest, followed by the yellow area, then the orange area, blue area, and gray area. It can be concluded that different sections have different importance, and weights can be input for the rolling time calculation. In this paper, the weights are given for final connect tracks.

The distributing zone is composed of many differently slope sections. The basic rolling resistance and air resistance are changing along with speed variation when the car is rolling. To calculate the WART under dynamic accelerating conditions, the distributing zone is divided into a large number of small equal parts. In each small part, the basic rolling resistance and air resistance are assumed constant. With the speed, acceleration, and distance formula, the rolling time of each small part can be computed as follows:

$$
\begin{aligned}
& \Delta t=\frac{-v_{0}+\sqrt{v_{0}^{2}+2 a \Delta s}}{a}, \\
& v_{t}=v_{0}+a \Delta t,
\end{aligned}
$$

where $\Delta s$ is the length of the small part (m); $\Delta t$ is rolling time of car in small part (s); $v_{0}$ is the initial speed in the small part (humping speed is the original speed) $(\mathrm{m} / \mathrm{s}) ; v_{t}$ is end speed in the small part and also the initial speed of next small part $(\mathrm{m} / \mathrm{s}) ; a$ is acceleration $\left(\mathrm{m} / \mathrm{s}^{2}\right)$.

With the recursion calculation, the rolling time of each section can be obtained, and the WART of profile design calculating car can be computed as follows:

$$
T_{w}=\sum_{j=1}^{N_{\mathrm{sp}}} \Delta t_{j} \times c_{w}^{j},
$$

where $T_{w}$ is the WART (s); $\Delta t_{j}$ is the rolling time of small part $j(\mathrm{~s}) ; c_{w}^{j}$ is the weighting coefficient of small part $j ; N_{\mathrm{sp}}$ is the total number of small parts.

To get the acceleration $a$, an analysis of the forces is needed, as shown in Figure 4.

In Figure $4, \alpha$ is gradient angle of the slope $\left({ }^{\circ}\right) ; G_{c}$ is gravity $(\mathrm{N}) ; f_{p}$ and $f_{g}$ are the components of the forces in the normal direction and along the slope $(\mathrm{N}) ; f_{s}$ is the normal supporting force $(\mathrm{N}) ; f_{r}$ is total rolling resistance $(\mathrm{N})$.

Usually, $i \%$ is used to express the gradient, and the max gradient is usually less than 55\% in China. Therefore, the equation for $i \%$ can be got as follows:

$$
i \% \text { o } \operatorname{tg} \alpha \approx \sin \alpha,
$$

where $i$ is the gradient (downgrade of rolling direction is positive, and upgrade is negative) (\%o).

The value of $f_{g}$ and its acceleration can be calculated as follows:

$$
f_{g}=M \times g^{\prime} \times \sin \alpha \approx M g^{\prime} i \times 10^{-3},
$$




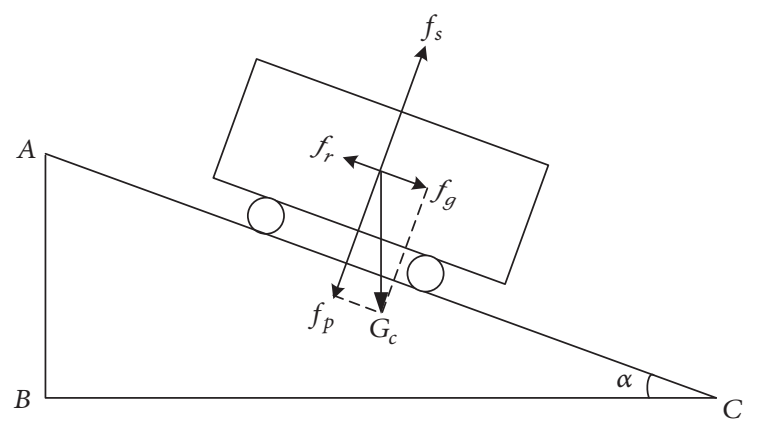

FIGURE 4: Force analysis of rolling car.

$$
a_{g}=\frac{f_{g}}{M}=g^{\prime} i \times 10^{-3},
$$

where $a_{g}$ is acceleration of $f_{g}\left(\mathrm{~m} / \mathrm{s}^{2}\right), M$ is car weight $(\mathrm{kg})$, and $g^{\prime}$ is the acceleration that takes into account rotational inertia $\left(\mathrm{m} / \mathrm{s}^{2}\right)$.

$$
g^{\prime}=\frac{g_{s}}{1+0.42 n_{\mathrm{axl}} /\left(M \times 10^{-3}\right)},
$$

where $g_{s}$ is standard gravity acceleration $\left(\mathrm{m} / \mathrm{s}^{2}\right)$ and $n_{\text {axl }}$ is the number of axles.

The total resistance consists of 4 parts: the rolling resistance, the air resistance, the turnout resistance, and the curve resistance, which can be calculated as follows:

$$
\begin{aligned}
f_{r}= & \left(w_{\text {rol }}+w_{\text {air }}+k_{\text {tur }} \times k_{\text {tur }}^{d} \times w_{\text {tur }}+k_{\text {cur }} \times w_{\text {cur }}\right) \\
& \times M \times g^{\prime} \times 10^{-3},
\end{aligned}
$$

where the $w_{\text {rol }}$ is the specific rolling resistance $(\mathrm{N} / \mathrm{kN}) ; w_{\text {air }}$ is the specific air resistance $(\mathrm{N} / \mathrm{kN}) ; w_{\text {tur }}$ is the specific turnout resistance $(\mathrm{N} / \mathrm{kN}) ; w_{\text {cur }}$ is the specific curve resistance $(\mathrm{N} / \mathrm{kN}) ; k_{\text {tur }}$ is the coefficient of turnout ( 1 when car rolls in the range of turnout, otherwise 0$) ; k_{\text {tur }}^{d}$ is the direction coefficient of turnout ( 1 for reverse turnout, 0.5 for forward turnout); $k_{\text {cur }}$ is the curve coefficient ( 1 when car rolls in the range of curve, otherwise 0 ).

The model for calculating specific rolling resistance can be obtained in [3].

The specific air resistance can be calculated as follows:

$$
w_{\text {air }}=\frac{0.063 s_{f} C_{x 1} / C_{x 0}}{M \times 10^{-3} \cos ^{2} \alpha_{\text {win }}}\left(v_{\text {car }} \pm v_{\text {win }} \cos \beta_{\text {win }}\right)^{2},
$$

where $s_{f}$ is front projected facade area of the rolling $\operatorname{car}\left(\mathrm{m}^{2}\right)$; $C_{x 1} / C_{x 0}$ is the coefficient of air resistance; $v_{c a r}$ is rolling speed $(\mathrm{m} / \mathrm{s}) ; v_{\text {win }}$ is wind speed (negative when the same as the rolling direction, and positive when opposite) $(\mathrm{m} / \mathrm{s}) ; \beta_{\text {win }}$ is the included angle of the wind and rolling direction $\left({ }^{\circ}\right) ; \alpha_{\text {win }}$ is the included angle of the compound direction (wind and rolling direction) and the rolling direction $\left({ }^{\circ}\right)$.

$\alpha_{\text {win }}$ can be calculated as follows:

$$
\alpha_{\text {win }}=\tan ^{-1} \frac{v_{\text {win }} \sin \beta}{v_{\text {car }} \pm v_{\text {win }} \cos \beta} .
$$

According to parameters in the "Code for Design on Hump and Marshalling Yard of Railway" ("the Code" for short) and assuming the resistance force of turnout and curve is constant, $w_{\text {tur }}$ is $1.375 \mathrm{~N} / \mathrm{kN}$, and $w_{\text {cur }}$ can be computed as follows:

$$
w_{\mathrm{cur}}=\frac{1440}{\pi \cdot R_{\mathrm{cur}}}
$$

where $R_{\text {cur }}$ is the radius of the curve (m).

Taking formulas (5) (10) together, according to Newtonian mechanics, the acceleration can be obtained:

$$
\begin{aligned}
a= & a_{g} \\
& -\left[w_{\text {rol }}+w_{\text {air }}+1.375 \times k_{\text {tur }} \times k_{\text {tur }}^{d}+\frac{1440}{\pi R_{\text {cur }}} k_{\text {cur }}\right] \\
& \times g^{\prime} \times 10^{-3} .
\end{aligned}
$$

The meaning of each symbol is similar to the former.

3.1.2. Height of Distributing Zone. Making rolling cars pass through the distributing zone as quickly as possible requires the gradients be as large as possible. However, this will make the height of the distributing zone too high, which will increase the difficulty of hump pushing for the locomotive and increase energy consumption. Therefore, the other optimization objective is to make the hump height as low as possible:

$$
H_{h}=\sum_{j=1}^{N_{\mathrm{sl}}}\left(x_{j}-x_{j-1}\right) i_{j} \times 10^{-3}
$$

where $H_{h}$ is the height of hump distributing zone $(\mathrm{m}) ; x_{j}$ is the $x$-coordinate of the $j$ th gradient change point; $x_{j-1}$ is the $x$-coordinate of the $(j-1)$ th gradient change point; and $N_{\mathrm{sl}}$ is the number of slopes; $i_{j}$ is the gradient of slope $j(\%)$.

\subsection{Model Constraints}

3.2.1. Gradient Change Point. According to the Code, the gradient change point should be kept away from the friction retarder, switch rails, and the frog. The shortest distance is along the tangent of vertical curve:

$$
L_{\mathrm{vta}}=\frac{R_{\mathrm{vc}} \Delta i}{2 \times 1000}
$$

where $L_{\mathrm{vta}}$ is length along the tangent $(\mathrm{m}) ; R_{\mathrm{vc}}$ is the radius of the vertical curve ( $250 \mathrm{~m}$ in the Code) (m); and $\Delta i$ is the value of the adjacent slope change (\%o).

Suppose that friction or turnout lies in front of the gradient change point:

$$
x_{\mathrm{gc}} \leq x_{\mathrm{start}}-L_{\mathrm{vta}}
$$

where $x_{\mathrm{gc}}$ is the $x$-coordinate of the gradient change point and $x_{\text {start }}$ is the starting $x$-coordinate of the gradient change point of friction or turnout. 
3.2.2. Max Entry Speed. With a $1.4 \mathrm{~m} / \mathrm{s}$ humping speed, under advantageous rolling condition, the easy rolling car's entry speed to turnout and the friction retarder is lower than the specified speed.

$$
\begin{aligned}
& v_{\mathrm{er}}^{\mathrm{ad}} \leq v_{\mathrm{fr}}^{\max }, \\
& v_{\mathrm{er}}^{\mathrm{ad}} \leq v_{\text {tur }}^{\max },
\end{aligned}
$$

where $v_{\mathrm{er}}^{\mathrm{ad}}$ is the rolling speed of the easy car under advantageous rolling conditions $(\mathrm{m} / \mathrm{s}) ; v_{\mathrm{fr}}^{\max }$ is the max allowed entry speed of friction retarder $(\mathrm{m} / \mathrm{s}) ; v_{\text {tur }}^{\max }$ is the max allowed entry speed of turnout $(\mathrm{m} / \mathrm{s})$.

3.2.3. Minimum Slope Where Friction Retarder Is Located. To make the car continue rolling if it is clamped to stop, the minimum slope where the friction retarder is located needs to be limited:

$$
I_{\text {ret }} \geq I_{\text {rol }}^{\mathrm{min}}
$$

where $I_{\text {ret }}$ is the slope at the friction retarder (\%o); $I_{\text {rol }}^{\min }$ is the minimum slope for hard rolling car automatic rolling (\%o).

3.2.4. Maximum and Minimum Gradient of Acceleration Section. Referring to the Code, the maximum and minimum gradient of the acceleration section should be limited:

$$
I_{\mathrm{acc}}^{\mathrm{min}} \leq I_{\mathrm{acc}} \leq I_{\mathrm{acc}}^{\mathrm{max}},
$$

where $I_{\mathrm{acc}}^{\mathrm{min}}$ and $I_{\mathrm{acc}}^{\mathrm{max}}$ are the limited minimum and maximum gradient $(\%) ; I_{\text {acc }}$ is the design gradient $(\% 0)$.

3.2.5. End Speed Limit. According to the Code, with a $1.4 \mathrm{~m} / \mathrm{s}$ humping speed and disadvantageous rolling conditions, the speed of the hard rolling car should not fall below a certain value at the end of distributing zone.

$$
v_{\text {end }}^{\text {hrd }} \geq v_{\text {end }}^{\text {spe }},
$$

where $v_{\text {end }}^{\text {hrd }}$ is the speed of the hard rolling car at the end of the distributing zone $(\mathrm{m} / \mathrm{s}) ; v_{\text {end }}^{\text {spe }}$ is the specified end speed $(\mathrm{m} / \mathrm{s})$.

3.2.6. Interval Time Limit of Hard-Mid Rolling Order. The hard-mid rolling order means that the front rolling car is the hard rolling car, and the car behind is the middle rolling car. For the middle rolling car runs faster than the hard rolling car, the interval time of the hard-mid rolling order will gradually be reduced, which leads to the risk of collision. The turnouts or friction does not have enough time to change the working status of the middle rolling car. The Code gives the limits that under disadvantageous rolling conditions and $1.4 \mathrm{~m} / \mathrm{s}$ humping speed, the hard-mid rolling order has a large enough time interval to pass the friction retarders and turnouts.

The popularly used point-continued speed control system in China has an interval braking point which can adjust the interval time for the hard-mid car rolling order, so the key section of track is the one from the hump crest to the first turnout and interval braking point:

$$
\begin{aligned}
& \frac{\left(L_{\mathrm{hrc}}+L_{\mathrm{mrc}}\right)}{2 v_{\mathrm{hum}}}-\left(t_{\mathrm{hr}}^{\mathrm{htt}}-t_{\mathrm{mr}}^{\mathrm{htt}}\right) \geq t_{\mathrm{tur}}, \\
& \frac{\left(L_{\mathrm{hrc}}+L_{\mathrm{mrc}}\right)}{2 v_{\mathrm{hum}}}-\left(t_{\mathrm{hr}}^{\mathrm{htr}}-t_{\mathrm{mr}}^{\mathrm{htr}}\right) \geq t_{\mathrm{ret}}^{\mathrm{inv}},
\end{aligned}
$$

where $L_{\mathrm{hrc}}$ and $L_{\mathrm{mrc}}$ are length of hard rolling car and middle rolling car (m); $v_{\text {hum }}$ is humping speed $(\mathrm{m} / \mathrm{s}) ; t_{\mathrm{hr}}^{\mathrm{htt}}$ and $t_{\mathrm{mr}}^{\mathrm{htt}}$ are the rolling time of hard rolling car and middle rolling car from the top of hump to the first turnout (s); $t_{\mathrm{hr}}^{\mathrm{htr}}$ and $t_{\mathrm{mr}}^{\mathrm{htr}}$ are the rolling time of hard rolling car and middle rolling car from the hump crest to the first friction retarder (s). $t_{\text {tur }}$ is the turnout working status change time $(s)$; $t_{\text {ret }}^{\text {inv }}$ is the friction retarder working status change time (s).

3.2.7. Slope Length Limit. For convenience of maintenance work, the minimum slope length needs to be limited.

$$
x_{\mathrm{fp}}-x_{\mathrm{bp}}>l_{\min }^{\mathrm{g}},
$$

where $x_{\mathrm{fp}}$ and $x_{\mathrm{bp}}$ are the $x$-coordinate of front slope change point and the back slope change point; $l_{\min }^{g}$ is minimum slope length $(\mathrm{m})$.

The profile design optimization model of the hump distributing zone can be summarized as follows:

$$
\begin{aligned}
& \text { Obj. } \quad \min T_{w}=\sum_{j=1}^{N_{\text {sp }}} t_{j} \times c_{w}^{j}, \\
& \min H_{h}=\sum_{j=1}^{N_{\mathrm{sl}}}\left(x_{j}-x_{j-1}\right) i_{j} \times 10^{-3}, \\
& \text { S.t } \quad x_{\mathrm{gc}} \leq x_{\text {start }}-L_{\mathrm{vta}} \text {, } \\
& v_{\mathrm{er}}^{\mathrm{ad}} \leq v_{\mathrm{fr}}^{\max }, \\
& v_{\mathrm{er}}^{\mathrm{ad}} \leq v_{\mathrm{tur}}^{\max }, \\
& I_{\text {ret }} \geq I_{\text {rol }}^{\mathrm{min}} \text {, } \\
& I_{\mathrm{acc}}^{\min } \leq I_{\mathrm{acc}} \leq I_{\mathrm{acc}}^{\mathrm{max}}, \\
& v_{\text {end }}^{\text {hrd }} \geq v_{\text {end }}^{\text {spe }} \text {, } \\
& \frac{\left(L_{\mathrm{hrc}}+L_{\mathrm{mrc}}\right)}{2 v_{\mathrm{hum}}}-\left(t_{\mathrm{hr}}^{\mathrm{htt}}-t_{\mathrm{mr}}^{\mathrm{htt}}\right) \geq t_{\mathrm{tur}}, \\
& \frac{\left(L_{\mathrm{hrc}}+L_{\mathrm{mrc}}\right)}{2 v_{\mathrm{hum}}}-\left(t_{\mathrm{hr}}^{\mathrm{htr}}-t_{\mathrm{mr}}^{\mathrm{htr}}\right) \geq t_{\mathrm{ret}}^{\mathrm{inv}}, \\
& x_{\mathrm{fp}}-x_{\mathrm{bp}}>l_{\text {min }}^{g} .
\end{aligned}
$$

The meaning of each symbol is the same to the former.

3.3. Model Solution. The model belongs to the Multiobjective Optimization Problem (MOP). Its solution is the Pareto set 


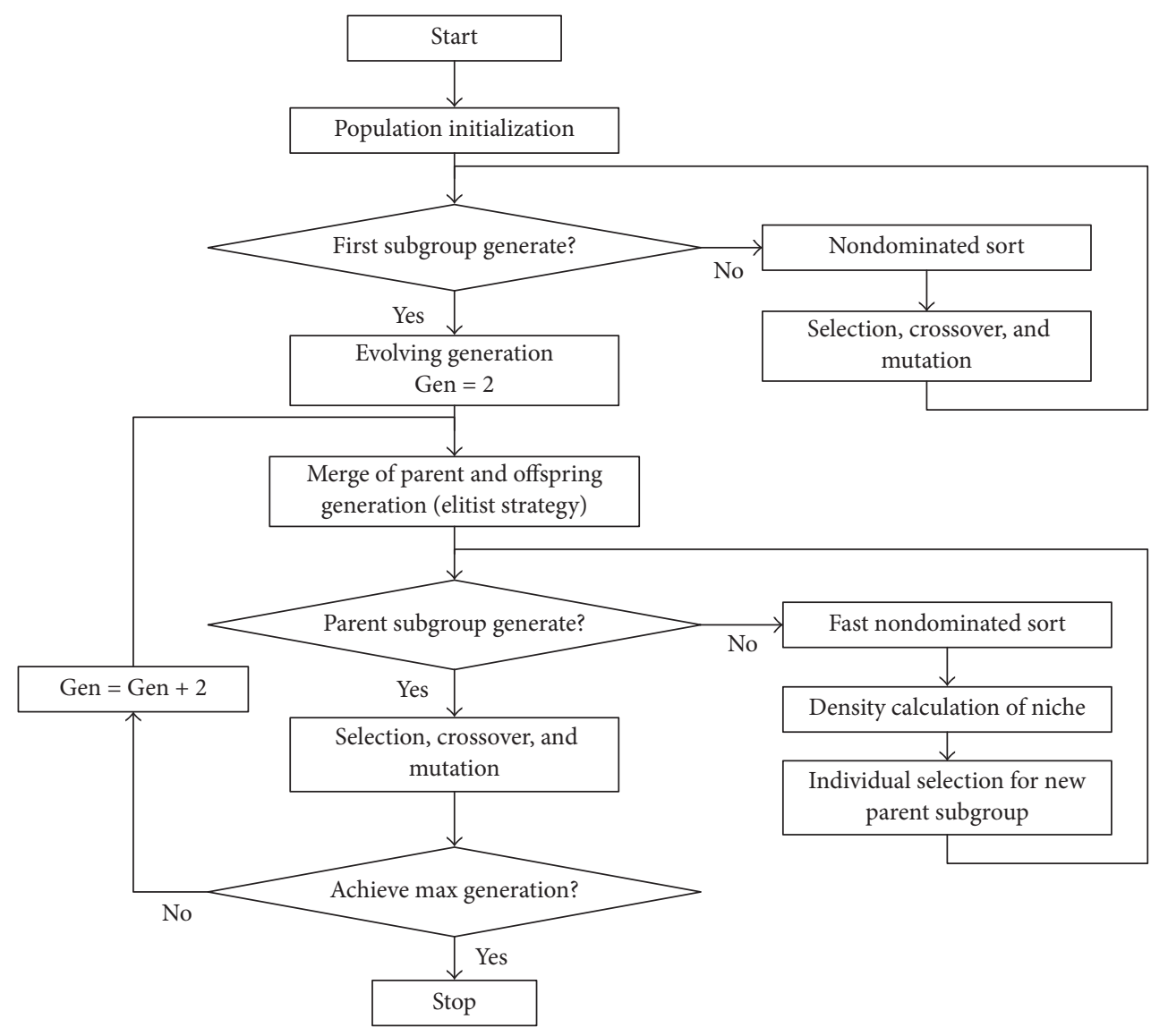

FIGURE 5: NSGA-II algorithm flow.

with no better solution than where one goal is optimized while another goal is degraded. The Nondominated Sorting Genetic Algorithm-II (NSGA-II) is used to get the Pareto solution set in this paper.

3.3.1. Algorithm Flow. The arithmetic flow chart is shown in Figure 5.

\subsubsection{Range of Decision Variable and Coding Rules}

(1) $x$-Coordinate of Gradient Change Point. The plane outspread drawing of hard rolling track is needed, and shown in Figure 6.

In Figure $6, \mathrm{P}_{1}$ is start point of hump profile design; $\mathrm{P}_{2}$, $\mathrm{P}_{8}, \mathrm{P}_{11}, \mathrm{P}_{16}, \mathrm{P}_{19}$, and $\mathrm{P}_{22}$ are the start points of curves; $\mathrm{P}_{3}, \mathrm{P}_{9}$, $\mathrm{P}_{12}, \mathrm{P}_{17}, \mathrm{P}_{20}$, and $\mathrm{P}_{23}$ are the end points of curves; $\mathrm{P}_{4}, \mathrm{P}_{5}, \mathrm{P}_{10}$, $\mathrm{P}_{15}, \mathrm{P}_{18}$, and $\mathrm{P}_{21}$ are the center coordinates of turnouts. $\mathrm{P}_{6}$; $\mathrm{P}_{13}$ and $\mathrm{P}_{24}$ are start points of friction retarders; $\mathrm{P}_{7}, \mathrm{P}_{14}$, and $\mathrm{P}_{25}$ are end points of friction retarders.

According to practical experience, if the first acceleration slope is less than $28 \mathrm{~m}$, the interval time will not be long enough and this will lead to a shunting accident. The length of switch rail and frog of $6 \#$ turnout are $7.437 \mathrm{~m}$ and $9.994 \mathrm{~m}$. The distributing zone can be roughly divided into three main sections with friction retarder as cutting points. The ranges of slope changing points can be limited as in Table 1.
(2) Range of Slopes. According to the Code and practical experience, the range of slopes can be limited and are shown in Table 2.

(3) Encoding Rules. Binary encoding is used in this paper. The encoding form is

$$
u_{k}=\left[i_{1}, i_{2}, \ldots, i_{N_{\mathrm{sl}}}, x_{1}, x_{2}, \ldots, x_{N_{\mathrm{sl}}}\right],
$$

where $u_{k}$ is the $k$ th chromosome.

The range of the gradient is $-1 \% 0 \sim 55 \%$, and the accuracy is $0.1 \%$. Considering the model calculation, the range is converted to $[0,560]$.

The gradient convert formula is

$$
i^{\prime}=(i+1) \times 10,
$$

where $i^{\prime}$ is the converted slope gradient (\%o).

The binary code length can be calculated as follows:

$$
\begin{aligned}
& 2^{\lambda_{i}}=\frac{560-0}{1}+1=561, \\
& \lambda_{i}=10
\end{aligned}
$$

where $\lambda_{i}$ is the binary code length of the gradient.

With regard to the length of the slope, for maintenance work convenience, the slopes are integers except the last one. The accuracy of encoding is $1 \mathrm{~m}$, and its range of lengths is $15 \sim 200 \mathrm{~m}$, the binary code length is 8 . 


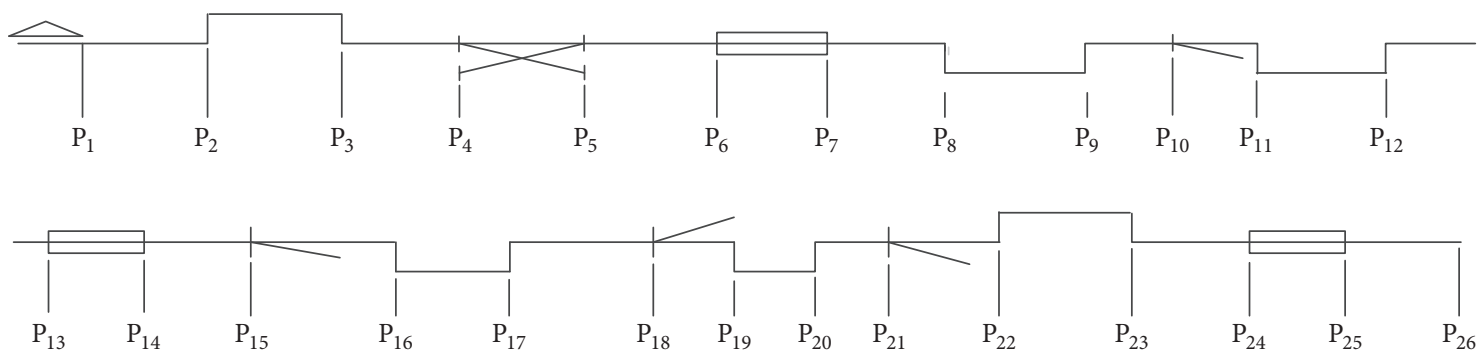

FIGURE 6: Sketch map of plane outspread drawing of hard rolling track.

TABLE 1: Ranges of slope changing points.

\begin{tabular}{|c|c|}
\hline Section type & Ranges of changing point \\
\hline Acceleration & {$\left[28, x_{\mathrm{p}_{2}}-L_{\mathrm{vta}}\right] \cup\left[x_{\mathrm{p}_{2}}+L_{\mathrm{vta}}, x_{\mathrm{p}_{3}}-L_{\mathrm{vta}}\right] \cup\left[x_{\mathrm{p}_{3}}+L_{\mathrm{vta}}, x_{\mathrm{p}_{4}}-7.437-L_{\mathrm{vta}}\right] \cup\left[x_{\mathrm{p}_{5}}+7.437+L_{\mathrm{vta}}, x_{\mathrm{p}_{6}}-L_{\mathrm{vta}}\right]$} \\
\hline High-speed rolling & $\begin{array}{c}{\left[x_{\mathrm{p}_{7}}+L_{\mathrm{vta}}, x_{\mathrm{p}_{8}}-L_{\mathrm{vta}}\right] \cup\left[x_{\mathrm{p}_{8}}+L_{\mathrm{vta}}, x_{\mathrm{p}_{9}}-L_{\mathrm{vta}}\right] \cup\left[x_{\mathrm{p}_{9}}+L_{\mathrm{vta}}, x_{\mathrm{p}_{10}}-7.437-L_{\mathrm{vta}}\right] \cup\left[x_{\mathrm{p}_{10}}+9.994+L_{\mathrm{vta}}\right.} \\
\left.x_{\mathrm{p}_{11}}-L_{\mathrm{vta}}\right] \cup\left[x_{\mathrm{p}_{11}}+L_{\mathrm{vta}}, x_{\mathrm{p}_{12}}-L_{\mathrm{vta}}\right] \cup\left[x_{\mathrm{p}_{12}}+L_{\mathrm{vta}}, x_{\mathrm{p}_{13}}-L_{\mathrm{vta}}\right]\end{array}$ \\
\hline Deceleration & $\begin{array}{c}{\left[x_{\mathrm{p}_{14}}+L_{\mathrm{vta}}, x_{\mathrm{p}_{15}}-7.437-L_{\mathrm{vta}}\right] \cup\left[x_{\mathrm{p}_{15}}+9.994+L_{\mathrm{vta}}, x_{\mathrm{p}_{16}}-L_{\mathrm{vta}}\right] \cup\left[x_{\mathrm{p}_{16}}+L_{\mathrm{vta}}, x_{\mathrm{p}_{17}}-L_{\mathrm{vta}}\right] \cup\left[x_{\mathrm{p}_{17}}+L_{\mathrm{vta}},\right.} \\
\left.x_{\mathrm{p}_{18}}-7.437-L_{\mathrm{vta}}\right] \cup\left[x_{\mathrm{p}_{18}}+9.994+L_{\mathrm{vta}}, x_{\mathrm{p}_{19}}-L_{\mathrm{vta}}\right] \cup\left[x_{\mathrm{p}_{19}}+L_{\mathrm{vta}}, x_{\mathrm{p}_{20}}-L_{\mathrm{vta}}\right] \cup\left[x_{\mathrm{p}_{20}}+L_{\mathrm{vta}},\right. \\
\left.x_{\mathrm{p}_{21}}-7.437-L_{\mathrm{vta}}\right] \cup\left[x_{\mathrm{p}_{21}}+9.994+L_{\mathrm{vta}}, x_{\mathrm{p}_{22}}-L_{\mathrm{vta}}\right] \cup\left[x_{\mathrm{p}_{22}}+L_{\mathrm{vta}}, x_{\mathrm{p}_{23}}-L_{\mathrm{vta}}\right] \cup\left[x_{\mathrm{p}_{23}}+L_{\mathrm{vta}}, x_{\mathrm{p}_{24}}-L_{\mathrm{vta}}\right]\end{array}$ \\
\hline
\end{tabular}

TABLE 2: Range of slopes.

\begin{tabular}{lccc}
\hline Section type & Acceleration & High-speed rolling & Deceleration \\
\hline Gradient (\%o) & $35 \% 0 \sim 55 \% 0$ & $5 \% 0 \sim 20 \% 0$ & $-1 \% 0 \sim 5 \% 0$ \\
\hline
\end{tabular}

TABLE 3: Friction retarder technical parameters.

\begin{tabular}{lcccc}
\hline Type & $\mathrm{T} \cdot \mathrm{JK} 2$ & $\mathrm{~T} \cdot \mathrm{JK} 2-\mathrm{A}(50)$ & $\mathrm{T} \cdot \mathrm{JK}$ & $\mathrm{T} \cdot \mathrm{JK} 3-\mathrm{A}(50)$ \\
\hline $\begin{array}{l}\text { Braking action time } \\
\quad\end{array}$ & & & & \\
$\quad$ Braking(s) & 0.6 & 0.6 & $0.6 \sim 1.0$ & 0.8 \\
$\quad$ Full braking(s) & & & 1.4 & \\
Release action time & & & & \\
$\quad$ Release(s) & 0.5 & 0.4 & $0.8 \sim 1.23$ & 0.4 \\
$\quad$ Full release(s) & 0.9 & 0.6 & 1.94 & 0.8 \\
\hline
\end{tabular}

\subsection{Calculation of Parameters}

3.4.1. Friction Retarder. In China, the popular friction retarder types are the T.JK, T.JK2-A(50), and TJK3-A(50). Their technical parameters are shown in Table 3.

3.4.2. Turnout Parameters. In China, the main turnout switch equipment is an electropneumatic switch machine in the distributing zone. Taking the ZK3 for reference, the turnout switching time is less than $0.6 \mathrm{~s}$.

3.4.3. Other Parameters. The parameters of temperature, wind speed and calculation car depend on the specific hump.

\section{Case Study}

Taking a 36-track (34 tracks are used for rolling) hump for example. The plane outspread drawing of hard rolling track of the distributing zone is shown in Figure 7 . The $x$-coordinate of each node is shown in Table 4.

Curve parameters of hard rolling track are shown in Table 5.

Consider too many slopes can affect the car rolling and increase the amount of hump maintenance work. Referring the Code, 6 slopes are set in this paper.

The climate conditions are shown in Table 6.

According to the data of Table 4, the range of the gradient change point, and the number of slopes, the range of the slope changing point can be got as shown in Table 7.

Given the small ranges of $x_{2}$ and $x_{6}$, the coordinates of $x_{2}$ and $x_{6}$ are given fixed values of $83.000 \mathrm{~m}$ and $393.660 \mathrm{~m}$.

For the WART calculation, the connect track number and the $x$-coordinate of branching turnout are given as Table 8 .

Equilateral turnout has lead curve, the hump uses 6\# equilateral turnout, and its radius and angle are $180 \mathrm{~m}$ and $4.731^{\circ}$. The $x$-coordinates of each turnout are given in Table 9.

The hard rolling car is the P70 with $9.82 \mathrm{~m}^{2}$ facade area and $30 \mathrm{t}$ total weight. The middle rolling car is a gondola car with $5.94 \mathrm{~m}^{2}$ facade area and $70 \mathrm{t}$ total weight. The $\max$ entry speed of turnout and friction retarder is $6.5 \mathrm{~m} / \mathrm{s}$. The minimum slope of friction retarder is $2 \%$. The end speed of the optimization area is $3.6 \mathrm{~m} / \mathrm{s}$. The selected and sorted typical Pareto solution set and traditional manual method result with 5 slopes are shown in Table 10.

As seen in Table 10, the Pareto solution set is numbers (1) (20), and the traditional manual method is number (21). The hump height of number (10) is almost the same with number (21), but the Pareto solution has a low WART value with 798.674 compared with 827.582. So, the optimization effect is obvious because the WART has a large cardinal number. Also, compared with traditional manual method, the method proposed in this paper can be worked out by computer, which is more convenient and save much time. 

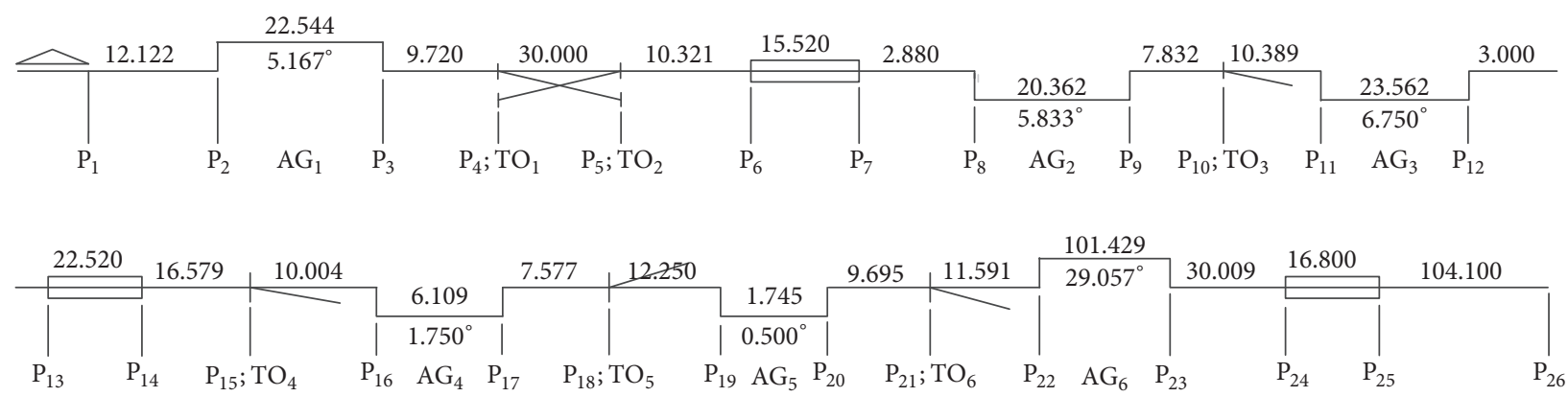

Figure 7: Plane outspread drawing of hard rolling track (sketch map).

TABLE 4: The $x$-coordinate of each node.

\begin{tabular}{lc}
\hline Number & $x$-coordinate \\
\hline $\mathrm{P}_{1}$ & 0.000 \\
$\mathrm{P}_{2}$ & 12.122 \\
$\mathrm{P}_{3}$ & 34.666 \\
$\mathrm{P}_{4}$ & 44.386 \\
$\mathrm{P}_{5}$ & 74.386 \\
$\mathrm{P}_{6}$ & 84.707 \\
$\mathrm{P}_{7}$ & 100.227 \\
$\mathrm{P}_{8}$ & 103.107 \\
$\mathrm{P}_{9}$ & 123.469 \\
$\mathrm{P}_{10}$ & 131.301 \\
$\mathrm{P}_{11}$ & 141.690 \\
$\mathrm{P}_{12}$ & 165.252 \\
$\mathrm{P}_{13}$ & 168.252 \\
$\mathrm{P}_{14}$ & 190.772 \\
$\mathrm{P}_{15}$ & 207.351 \\
$\mathrm{P}_{16}$ & 217.355 \\
$\mathrm{P}_{17}$ & 223.464 \\
$\mathrm{P}_{18}$ & 231.041 \\
$\mathrm{P}_{19}$ & 243.291 \\
$\mathrm{P}_{20}$ & 245.036 \\
$\mathrm{P}_{21}$ & 254.731 \\
$\mathrm{P}_{22}$ & 266.322 \\
$\mathrm{P}_{23}$ & 367.751 \\
$\mathrm{P}_{24}$ & 397.760 \\
$\mathrm{P}_{25}$ & 414.560 \\
$\mathrm{P}_{26}$ & 518.660 \\
\hline & \\
&
\end{tabular}

\section{Conclusions}

This paper focuses on the hump profile optimization problem. Based on the analysis of the hump distributing zone and the importance of each part, a model was established with the smallest WART and the lowest of hump height selected as optimization objectives, with the gradients change points, Maximum Entry Speed, and so on, as constraints. The NSGA-II algorithm was imported for model solution. In the case study, a comparison is made between the method proposed in this paper and traditional manual method, and the optimization effect is significant.

\section{Symbols}

$\Delta s: \quad$ Length of the small part $(\mathrm{m})$

$v_{0}$ : Initial speed in the small part (humping speed is the original speed) $(\mathrm{m} / \mathrm{s})$

$a: \quad$ Acceleration $\left(\mathrm{m} / \mathrm{s}^{2}\right)$

$\Delta t_{j}$ : Rolling time of small part $j(\mathrm{~s})$

$N_{\mathrm{sp}}$ : Total number of small parts

$G_{c}:$ Gravity $(\mathrm{N})$

$f_{g}$ : Components of the forces along the slope $(\mathrm{N})$

$f_{r}: \quad$ Total rolling resistance $(\mathrm{N})$

$i$ : $\quad$ Gradient (downgrade of rolling direction is positive; upgrade is negative) (\%o)

$M$ : $\quad$ Car weight $(\mathrm{kg})$

$n_{\text {axl }}:$ Number of axles

$w_{\text {air }}:$ Specific air resistance $(\mathrm{N} / \mathrm{kN})$

$w_{\text {cur }}:$ Specific curve resistance $(\mathrm{N} / \mathrm{kN})$

$k_{\text {tur }}$ : Coefficient of turnout (1 when car rolls in the range of turnout, otherwise 0 )

$k_{\text {cur }}$ : Curve coefficient ( 1 when car rolls in the range of curve, otherwise 0 )

$v_{\text {car }}:$ Rolling speed $(\mathrm{m} / \mathrm{s})$

$v_{\text {win }}$ : Wind speed (negative when the same as the rolling direction and positive when opposite) $(\mathrm{m} / \mathrm{s})$

$\beta_{\text {win }}$ : Included angle of the wind and rolling direction $\left(^{\circ}\right)$

$x_{j-1}: x$-coordinate of the $(j-1)$ th gradient change point

$i_{j}: \quad$ Slope gradient of slope $j(\% 0)$

$R_{\mathrm{vc}}:$ Radius of the vertical curve $(\mathrm{m})$

$x_{\mathrm{gc}}: x$-coordinate of the gradient change point

$v_{\mathrm{er}}^{\mathrm{ad}}$ : Rolling speed of the easy car under advantageous rolling conditions $(\mathrm{m} / \mathrm{s})$

$v_{\text {tur }}^{\max }:$ Max allowed entry speed of turnout $(\mathrm{m} / \mathrm{s})$

$I_{\text {rol }}^{\min }:$ Minimum slope for hard rolling car automatic rolling (\%o)

$I_{\text {acc }}^{\min }$ : Limited minimum gradient (\%o)

$I_{\text {acc }}$ : Design gradient (\%o)

$L_{\mathrm{hrc}}:$ Lengths of the hard rolling car (m) 
TABLE 5: Curve parameters of hard rolling track.

\begin{tabular}{|c|c|c|c|c|c|c|}
\hline Number & Angle $\left(^{\circ}\right)$ & Radius (m) & Tangent length (m) & Curve length (m) & Start $x$-coordinate & End $x$-coordinate \\
\hline $\mathrm{AG}_{1}$ & 5.167 & 250 & 11.280 & 22.544 & 12.122 & 34.666 \\
\hline $\mathrm{AG}_{2}$ & 5.833 & 200 & 10.190 & 20.362 & 103.107 & 123.469 \\
\hline $\mathrm{AG}_{3}$ & 6.750 & 200 & 11.795 & 23.562 & 141.69 & 165.252 \\
\hline $\mathrm{AG}_{4}$ & 1.750 & 200 & 3.054 & 6.109 & 217.355 & 223.464 \\
\hline $\mathrm{AG}_{5}$ & 0.500 & 200 & 0.873 & 1.745 & 243.291 & 245.036 \\
\hline $\mathrm{AG}_{6}$ & 29.057 & 200 & 51.773 & 101.429 & 266.322 & 367.751 \\
\hline
\end{tabular}

TABLE 6: Climate conditions of hump design.

\begin{tabular}{lccc}
\hline Condition & Temperature $\left({ }^{\circ} \mathrm{C}\right)$ & Wind speed $(\mathrm{m} / \mathrm{s})$ & Wind direction $\left({ }^{\circ}\right)$ \\
\hline Disadvantageous & -5 & 4 & 0 \\
Advantageous & 27 & -3 & 0 \\
\hline
\end{tabular}

TABLE 7: Reasonable range of slope changing point.

\begin{tabular}{lc}
\hline Slope change point & Ranges \\
\hline$x_{1}$ & {$\left[28.000,34.666-L_{\mathrm{vta}}\right]$} \\
$x_{2}$ & {$\left[81.823+L_{\mathrm{vta}}, 84.707-L_{\mathrm{vta}}\right]$} \\
$x_{3}$ & {$\left[103.107+L_{\mathrm{vta}}, 123.469-L_{\mathrm{vta}}\right] \cup\left[141.690+L_{\mathrm{vta}}, 165.252-L_{\mathrm{vta}}\right]$} \\
$x_{4}$ & {$\left[190.772+L_{\mathrm{vta}}, 199.914-L_{\mathrm{vta}}\right]$} \\
$x_{5}$ & {$\left[266.322+L_{\mathrm{vta}}, 367.751-L_{\mathrm{vta}}\right]$} \\
$x_{6}$ & $397.760-L_{\mathrm{vta}}$ \\
\hline
\end{tabular}

TABLE 8: Connect track number and the $x$-coordinate of branching turnout.

\begin{tabular}{lccc}
\hline Branching turnout & Connect tracks & $x$-coordinate & Value \\
\hline$x_{t 1}$ & 34 & $x_{p_{4}}+9.994$ & 54.380 \\
$x_{t 2}$ & 17 & $x_{p_{10}}+9.994$ & 141.295 \\
$x_{t 3}$ & 5 & $x_{\mathrm{p}_{15}}+9.994$ & 217.345 \\
$x_{t 4}$ & 2 & $x_{\mathrm{p}_{21}}+9.994$ & 264.725 \\
\hline
\end{tabular}

TABLE 9: Turnouts $x$-coordinates.

\begin{tabular}{lcc}
\hline Number & Start $x$-coordinate & End $x$-coordinate \\
\hline TO1 & 36.949 & 54.38 \\
TO2 & 64.392 & 81.823 \\
TO3 & 123.864 & 141.295 \\
TO4 & 199.914 & 217.345 \\
TO5 & 223.604 & 241.035 \\
TO6 & 247.294 & 264.725 \\
\hline
\end{tabular}

$v_{\text {hum }}$ : Humping speed $(\mathrm{m} / \mathrm{s})$

$t_{\mathrm{hr}}^{\mathrm{htt}}: \quad$ Rolling time of hard rolling car from the top of hump to the first turnout (s)

$t_{\mathrm{hr}}^{\mathrm{htr}}$ : Rolling time of the hard rolling car from the top of hump to the first friction retarder (s)

$t_{\text {ret }}^{\text {inv }}$ Friction retarder working status change time (s)

$x_{\mathrm{bp}}: \quad x$-coordinate of back slope change point

$u_{k}$ : The $k$ th chromosome

$\lambda_{i}$ : Binary code length of the gradient
$\Delta t: \quad$ Rolling time of car in small part (s)

$v_{t}$ : $\quad$ End speed in the small part and also the initial speed of next small part $(\mathrm{m} / \mathrm{s})$

$T_{w}: \quad$ The WART (s)

$c_{w}^{j}$ : $\quad$ Weighting coefficient of small part $j$

$\alpha: \quad$ Gradient angle of the slope $\left({ }^{\circ}\right)$

$f_{s}$ : $\quad$ Normal supporting force $(\mathrm{N})$

$f_{p}$ : Components of the forces in the normal direction $(\mathrm{N})$

$a_{g}: \quad$ Acceleration of $f_{g}\left(\mathrm{~m} / \mathrm{s}^{2}\right)$

$g^{\prime}$ : Acceleration that takes into account rotational inertia $\left(\mathrm{m} / \mathrm{s}^{2}\right)$

$g_{s}: \quad$ Standard gravity acceleration $\left(\mathrm{m} / \mathrm{s}^{2}\right)$

$w_{\text {rol }}: \quad$ Specific rolling resistance $(\mathrm{N} / \mathrm{kN})$

$w_{\text {tur }}: \quad$ Specific turnout resistance $(\mathrm{N} / \mathrm{kN})$

$C_{x 1} / C_{x 0}$ : Coefficient of air resistance

$k_{\text {tur }}^{d}$ : $\quad$ Direction coefficient of turnout (1 for reverse turnout, 0.5 for forward turnout)

$s_{f}$ : $\quad$ Front projected facade area of the rolling car $\left(\mathrm{m}^{2}\right)$ 
TABLE 10: Solution set with two methods of hump profile design of distributing zone.

\begin{tabular}{|c|c|c|c|c|c|c|c|c|c|c|c|c|c|c|}
\hline No. & $\begin{array}{c}S 1 \\
\left(10^{-3}\right)\end{array}$ & $\begin{array}{c}S 2 \\
\left(10^{-3}\right)\end{array}$ & $\begin{array}{c}S 3 \\
\left(10^{-3}\right)\end{array}$ & $\begin{array}{c}S 4 \\
\left(10^{-3}\right)\end{array}$ & $\begin{array}{c}S 5 \\
\left(10^{-3}\right)\end{array}$ & $\begin{array}{c}S 6 \\
\left(10^{-3}\right)\end{array}$ & $X 1$ & $X 2$ & $X 3$ & $X 4$ & $X 5$ & $X 6$ & $\mathrm{HH}$ & WART \\
\hline (1) & 54.7 & 18.4 & 8.7 & 8.0 & 5.5 & 1.5 & 30 & 83 & 110 & 196 & 310 & 393.66 & 4.255 & 778.827 \\
\hline (2) & 54.8 & 17.8 & 6.7 & 2.7 & 9.0 & 0.6 & 30 & 83 & 164 & 198 & 302 & 393.66 & 4.213 & 780.720 \\
\hline (3) & 54.9 & 18.2 & 5.0 & 5.0 & 6.1 & 3.6 & 30 & 83 & 114 & 193 & 298 & 393.66 & 4.147 & 783.875 \\
\hline (4) & 53.2 & 19.1 & 7.9 & 7.9 & 4.0 & 0.4 & 30 & 83 & 146 & 197 & 348 & 393.66 & 4.097 & 786.410 \\
\hline (5) & 54.5 & 16.7 & 9.4 & 7.4 & 2.5 & 3.3 & 30 & 83 & 144 & 198 & 307 & 393.66 & 4.014 & 787.948 \\
\hline (6) & 53.4 & 18.9 & 3.3 & 9.3 & 4.2 & 2.5 & 30 & 83 & 144 & 195 & 313 & 393.66 & 3.977 & 791.551 \\
\hline (7) & 54.0 & 19.9 & 3.8 & 3.8 & 6.7 & -0.2 & 28 & 83 & 113 & 194 & 324 & 393.66 & 3.885 & 794.150 \\
\hline (8) & 54.9 & 17.2 & 1.7 & 7.9 & 3.8 & 2.0 & 29 & 83 & 113 & 198 & 325 & 393.66 & 3.863 & 795.772 \\
\hline (9) & 54.1 & 16.3 & 9.9 & 2.1 & 4.2 & 1.8 & 28 & 83 & 159 & 199 & 274 & 393.66 & 3.778 & 797.065 \\
\hline (10) & 54.5 & 18.8 & 4.5 & 2.0 & 3.8 & 3.5 & 28 & 83 & 163 & 194 & 352 & 393.66 & 3.728 & 798.674 \\
\hline (11) & 54.7 & 16.2 & 2.1 & 6.2 & 3.4 & 2.8 & 30 & 83 & 116 & 197 & 295 & 393.66 & 3.681 & 800.504 \\
\hline (12) & 54.2 & 18.1 & 2.9 & 3.6 & 4.8 & 1.1 & 29 & 83 & 160 & 199 & 335 & 393.66 & 3.630 & 803.904 \\
\hline (13) & 54.8 & 15.8 & 4.6 & 5.1 & 3.6 & 1.9 & 29 & 83 & 164 & 195 & 332 & 393.66 & 3.584 & 806.544 \\
\hline (14) & 52.4 & 19.4 & 3.9 & 6.1 & 2.1 & 2.5 & 28 & 83 & 154 & 198 & 346 & 393.66 & 3.510 & 809.348 \\
\hline (15) & 51.7 & 18.4 & 4.4 & 4.0 & 4.4 & 0.9 & 29 & 83 & 145 & 196 & 292 & 393.66 & 3.484 & 813.706 \\
\hline (16) & 54.8 & 15.9 & 0.0 & 4.5 & 3.6 & 2.3 & 29 & 83 & 112 & 198 & 288 & 393.66 & 3.402 & 816.304 \\
\hline (17) & 53.0 & 12.2 & 8.1 & 9.3 & 1.4 & -0.1 & 28 & 83 & 144 & 197 & 340 & 393.66 & 3.337 & 829.300 \\
\hline (18) & 52.0 & 13.7 & 5.9 & 9.3 & 5.8 & -0.9 & 28 & 83 & 160 & 192 & 268 & 393.66 & 3.289 & 833.284 \\
\hline (19) & 51.6 & 12.5 & 6.2 & 6.7 & 2.0 & 1.5 & 29 & 83 & 112 & 199 & 280 & 393.66 & 3.267 & 840.509 \\
\hline (20) & 54.1 & 10.0 & 6.9 & 4.6 & 2.5 & 1.9 & 28 & 83 & 165 & 198 & 352 & 393.66 & 3.247 & 843.870 \\
\hline$(21)$ & 50 & 16 & 8 & 6 & 3 & - & 28 & 83 & 168 & 185 & 393.66 & - & 3.717 & 827.582 \\
\hline
\end{tabular}

$H_{h}$ : Height of the hump distributing zone (m)

$\alpha_{\text {win }}$ : Included angle of the compound direction (wind and rolling direction) and the rolling direction $\left(^{\circ}\right.$ )

$x_{j}: \quad x$-coordinate of the jth gradient change point

$x_{\text {start }}$ : Starting $x$-coordinate of the gradient change point of friction or turnout

$L_{\mathrm{vta}}$ : Length along the tangent (m)

$\Delta i$ : Value of the adjacent slope change (\%o)

$N_{\mathrm{sl}}$ : Number of slopes

$v_{\mathrm{fr}}^{\max }$ : Max allowed entry speed of the friction retarder $(\mathrm{m} / \mathrm{s})$

$I_{\text {ret }}: \quad$ Slope at the friction retarder (\%o)

$v_{\mathrm{end}}^{\text {hrd }}$ : Speed of the hard rolling car at the end of the distributing zone $(\mathrm{m} / \mathrm{s})$

$I_{\text {acc }}^{\text {max }}$ : Limited maximum gradient $(\% 0)$

$v_{\text {end }}^{\text {spe }}$ : Specified end speed $(\mathrm{m} / \mathrm{s})$

$L_{\text {mrc }}$ : Lengths of middle rolling car (m)

$t_{\text {tur }}$ : Turnout working status change time (s)

$t_{\mathrm{mr}}^{\mathrm{htt}}$ : Rolling time of middle rolling car from the top of hump to the first turnout (s)

$t_{\mathrm{mr}}^{\mathrm{htr}}$ : Rolling time of middle rolling car from the top of hump to the first friction retarder (s)

$x_{\mathrm{fp}}: x$-coordinate of front slope change point $l_{\min }^{g}:$ Minimum slope length $(\mathrm{m})$

$i^{\prime}$ : $\quad$ Converted slope gradient (\%o).

\section{Conflicts of Interest}

The authors declare that there are no conflicts of interest regarding the publication of this paper.

\section{Acknowledgments}

This research is supported by the National Natural Science Foundation of China Project (51308029) and the Fundamental Research Funds for the Central Universities (2017JBM036).

\section{References}

[1] China Railway SiYuan Survey and Design Group, Railway Station and Terminal, China Railway Publishing House, Beijing, China, 2004.

[2] Ministry of Railways of PRC, Code for Design on Hump and Marshalling Yard of Railway, China Railway Publishing House, 1999.

[3] H. L. Zhang, J. Yang, and T. Y. Yang, "The quadratic fitting method for the specific rolling resistance of cars running from hump based on report data," Code for Design on Hump and Marshalling Yard of Railway, vol. 42, no. 5, pp. 1808-1813, 2017.

[4] C. Zhang, "The analysis of impact of new over loading rolling stocks on hump operation and design," Retarders and Speed Control Technology, vol. 4, pp. 12-14, 2007. 
[5] Z. F. Bao, "Some Question and Countermeasure about Automatization System of Marshalling Yard Adapt Heavy-haul Train," Retarders and Speed Control Technology, vol. 3, pp. 17-21, 2008.

[6] Y. D. Sun, "The analysis of brake capability demand of retarders for hump rolling of new type wagon of 23-ton-axle load," Retarders and Speed Control Technology, vol. 6, pp. 1-6, 2006.

[7] C. M. Zhang, Y. Z. Li, Z. Z. Chen, X. F. Yang, and R. C. He, "Analysis on over-speed coupling accidents on hump based on Bayesian networks," Journal of the China Railway Society, vol. 33, no. 10, pp. 7-14, 2011.

[8] J. B. Wang, Y. S. Zhang, C. H. Tian, X. L. Jiang, and J. B. Wang, "Influence of Freight Train with 27t Axle Load on the Carrying Capacity of Existing Lines," China Railway Science, vol. 36, no. 2, pp. 91-97, 2014.

[9] X. S. Du and A. Di, "27t Axle Load Car humping Test and Hump Design Strategy," in Proceedings of the China Retarders Technological Innovation and Application Development Symposium Proceedings, Beijing, China, 2014.

[10] F. Chen, "The Analysis of the retarder speed control system on existing railway wagons of 27 tons of axle load," Retarders and Speed Control Technology, vol. 1, pp. 6-9, 2014.

[11] H. L. Zhang, H. Yang, P. Zhao, and Y. G. Wei, "Study on braking adaptability of hump spacing-braking retarder to large axle load general service freight car," Journal of the China Railway Society, vol. 35, no. 10, pp. 33-37, 2013.

[12] J.-A. Adlbrecht, B. Hüttler, J. Zazgornik, and M. Gronalt, "The train marshalling by a single shunting engine problem," Transportation Research Part C: Emerging Technologies, vol. 58, pp. 56-72, 2015.

[13] T. Shi and X. S. Zhou, "A mixed integer programming model for optimizing multi-level operations process in railroad yards," Transportation Research Part B: Methodological, vol. 80, pp. 1939, 2015.

[14] H. D. Li, M. Z. Jin, and S. W. He, "Sequencing and Scheduling in Railway Classification Yards," Transportation Research Record, vol. 2475, pp. 72-80, 2015.

[15] T. Bektaş, T. G. Crainic, and V. Morency, "Improving the performance of rail yards through dynamic reassignments of empty cars," Transportation Research Part C: Emerging Technologies, vol. 17, no. 3, pp. 259-273, 2009.

[16] C. T. Dick and J. R. Dirnberger, "Advancing the science of yard design and operations with the CSX hump yard simulation system," in Proceedings of the 2014 Joint Rail Conference, JRC 2014, 2014.

[17] S. Yagar, F. F. Saccomanno, and Q. Shi, "An efficient sequencing model for humping in a rail yard," Transportation Research Part A: General, vol. 17, no. 4, pp. 251-262, 1983.

[18] P. Marton, J. Maue, and M. Nunkesser, "An Improved Train Classification Procedure for the Hump Yard Lausanne Triage," in Proceedings of the Algorithmic Approaches for Transportation Modeling, Optimization, 2009.

[19] E. Lin and C. Cheng, "Simulation and analysis of railroad hump yards in North America," in Proceedings of the Winter Simulation Conference (WSC '11), 2011.

[20] N. Boysen, S. Emde, and M. Fliedner, "The basic train makeup problem in shunting yards," OR Spectrum, vol. 38, no. 1, pp. 207233, 2016

[21] H. L. Zhang, H. Yang, S. L. Xia, J. F. Wang, and R. H. Li, "Research on profile optimization design method for coupling area in marshalling yard under application of heavy haul freight car," Journal of the China Railway Society, vol. 38, no. 10, pp. 1419, 2016.
[22] H. L. Zhang, H. Yang, and S. L. Xia, "Effect of meteorological data accuracy on hump height design," Journal of Transportation Systems Engineering and Information Technology, vol. 15, no. 3, pp. 185-189, 2015.

[23] X. Z. Huang, Research on Theory of Marshalling Station CAD and System Fulfillment, Beijing Jiaotong University, 1998.

[24] C. M. Zhang, Optimization of Vertical Section Design for Automated Hump, Lanzhou Jiaotong University, 2011.

[25] K. Deb, S. Agrawal, A. Pratap, and T. Meyarivan, "A fast elitist non-dominated sorting genetic algorithm for multi-objective optimization: NSGA-II," Lecture Notes in Computer Science, vol. 1917, pp. 849-858, 2000.

[26] C. Zhang and X. Ma, "NSGA-II algorithm with a local search strategy for multiobjective optimal design of dry-type aircore reactor," Mathematical Problems in Engineering, vol. 2015, Article ID 839035, 2015.

[27] S. Li, N. Wang, Z. He, A. Che, and Y. Ma, "Design of a multiobjective reverse logistics network considering the cost and service level," Mathematical Problems in Engineering, vol. 2012, Article ID 928620, 21 pages, 2012. 


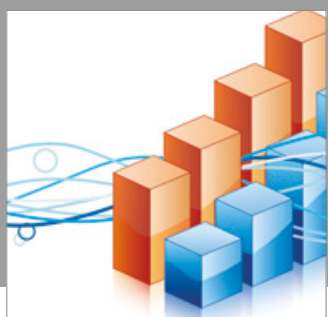

Advances in

Operations Research

vatersals

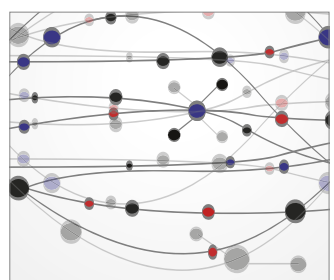

\section{The Scientific} World Journal
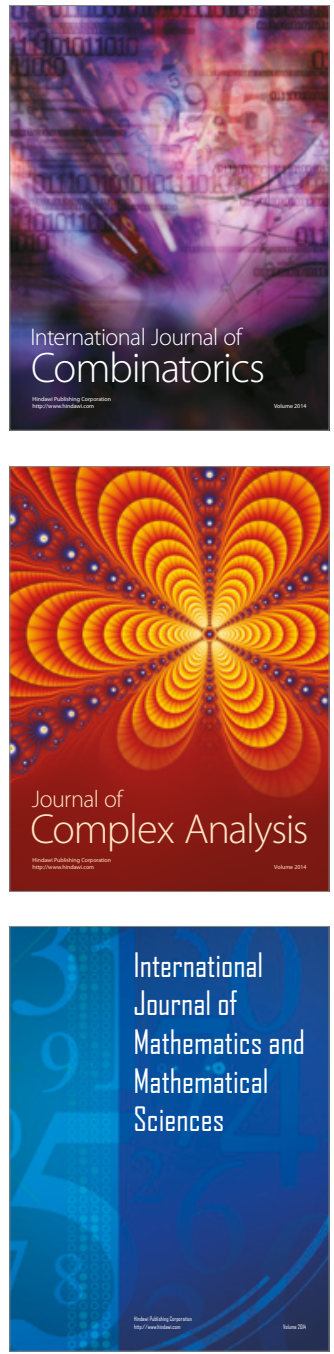
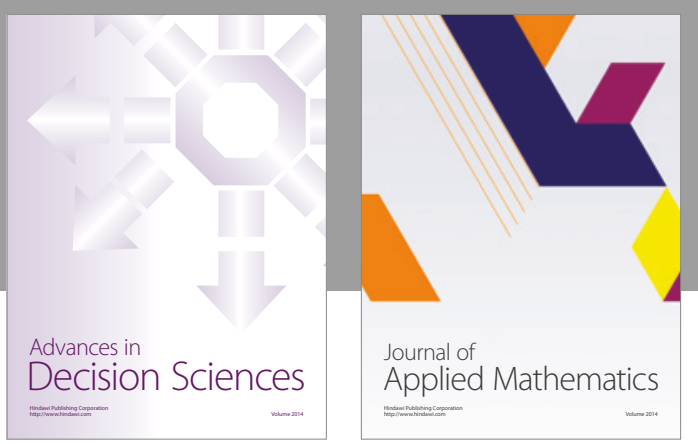

Algebra

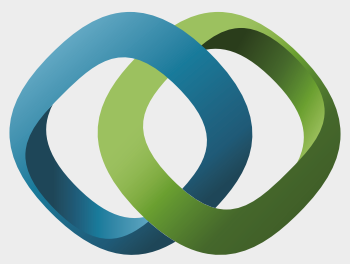

\section{Hindawi}

Submit your manuscripts at

https://www.hindawi.com
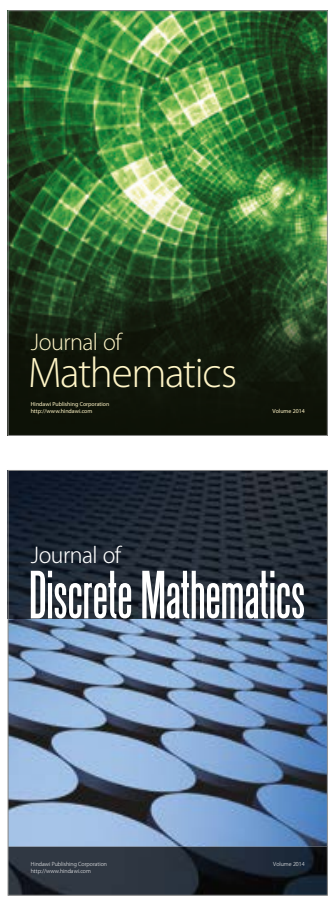

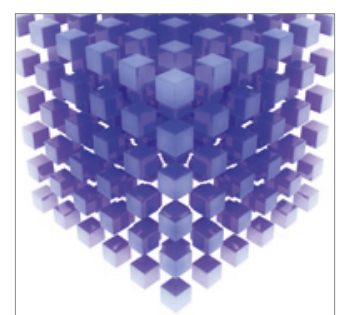

Mathematical Problems in Engineering
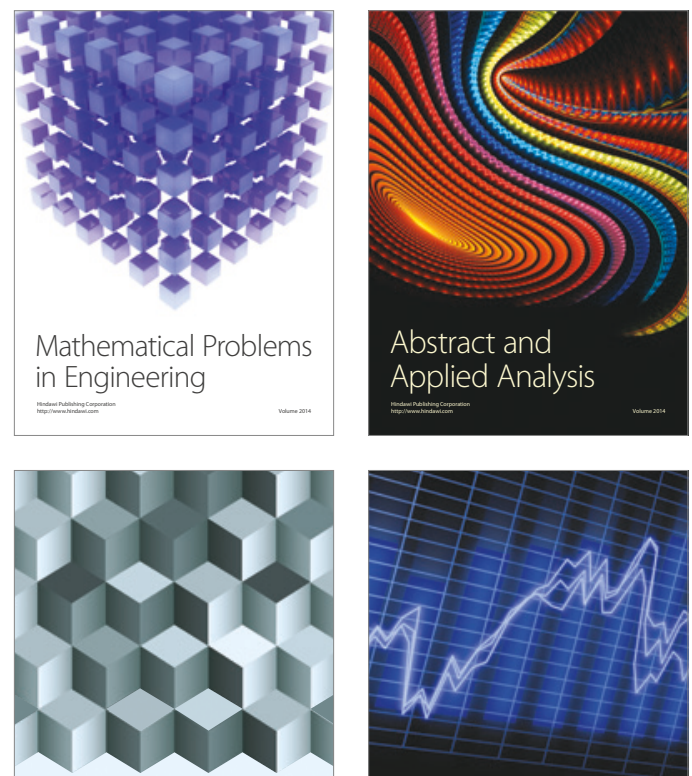

Journal of

Function Spaces

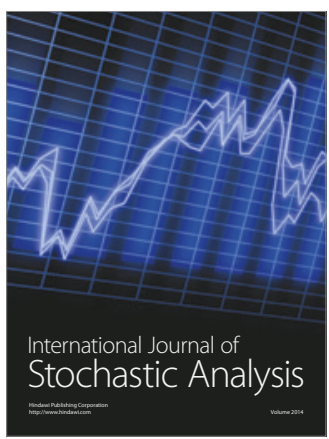

Probability and Statistics
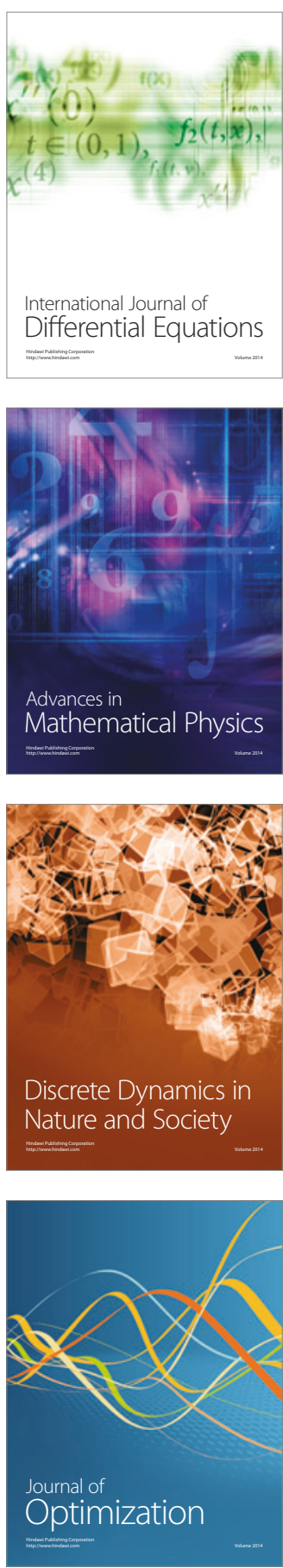